\title{
Fabrication and Thermoelectric Properties of Chromium Silicide Thin Films
}

\author{
Takao Mori, ${ }^{1,2^{*}}$ Takashi Aizawa, ${ }^{1}$ S. N. Vijayaraghavan, ${ }^{1}$ and Naoki Sato ${ }^{1}$ \\ ${ }^{1}$ WPI-MANA and CFSN, National Institute for Materials Science (NIMS), Namiki 1-1, Tsukuba 305-0044, Japan \\ ${ }^{2}$ Graduate School of Pure and Applied Sciences, University of Tsukuba, 1-1-1 Tennoudai, Tsukuba 305-8671, Japan
}

(Received March 30, 2020; accepted May 15, 2020)

Keywords: thermoelectric, thin film, magnetic semiconductor, power factor, thermal conductivity

Thermoelectric thin films are candidate materials that can be used to supply the energy harvested to autonomously power Internet of Things (IoT) sensors and devices. This work deals with the fabrication of chromium silicide thin films and the characterization of their thermoelectric properties. The films were grown by utilizing a high-temperature molecular beam epitaxy (MBE) apparatus under different conditions. The highest power factor of more than $0.6 \mathrm{~mW} / \mathrm{m} \mathrm{K}^{2}$ was obtained for the chromium silicide film deposited at a temperature of $900{ }^{\circ} \mathrm{C}$. The thermal conductivity of the thin film was observed to be approximately one-third that of bulk $\mathrm{CrSi}_{2}$.

\section{Introduction}

The application of thermoelectric power generation has still not been realized in a large market. In addition to the performance of power generation, cost has also been a big problem. One promising application that has gained interest is thermal energy harvesting to dynamically power innumerable Internet of Things (IoT) sensors and devices. ${ }^{(1,2)}$ In this case, the maintenance-free possibility of thermoelectrics is attractive, because changing batteries for a huge number of sensors and devices is not feasible. It is therefore important for IoT applications to find methods appropriate for processing and fabricating modules for high-performance materials. The use of inorganic thermoelectric thin films is one possibility.

The performance of thermoelectric materials is determined by their figure of merit:

$$
Z T=\alpha^{2} \sigma \kappa^{-1} T,
$$

where $\alpha^{2} \sigma$ is the power factor, and the conversion efficiency is a function of ZT. To achieve high $Z T$, a high electrical conductivity $\sigma$, but a low thermal conductivity $\kappa$, and a large Seebeck coefficient $\alpha$, but a high $\sigma$, are required. Therefore, there are some obvious paradoxes and trade-offs in the requirements of the physical properties of materials to achieve high thermoelectric performance. There have been several good overall reviews of recent advancements in enhancing the $Z T$ of thermoelectric materials. ${ }^{(3,4)}$

*Corresponding author: e-mail: MORI.Takao@nims.go.jp

https://doi.org/10.18494/SAM.2020.2889 
We have proposed the use of magnetism to enhance the properties of thermoelectric materials. Magnetic ion doping has been demonstrated for various systems, such as $\mathrm{CuGaTe}_{2},{ }^{(5)}$ $\mathrm{Bi}_{2} \mathrm{Te}_{3},{ }^{(6)}$ and $\mathrm{SnSe},{ }^{(7)}$ to be a possible route to increase the power factor. Such an increase is not automatic and occurs in cases where electrical carriers have strong coupling with doped magnetic moments, effectively modifying transport properties. Namely, this interaction "drags" the carriers, leading to an increase in effective mass that in turn increases the Seebeck coefficient. This will be detrimental to mobility, but the overall increase in power factor has been realized. ${ }^{(5-7)}$ Some good-performance thermoelectric compounds have also been recently discovered amongst magnetic semiconductors, where magnetic elements are the main constituents. ${ }^{(8-13)}$ Carrier-doped $\mathrm{CuFeS}_{2}$ exhibits a large power factor at room temperature (RT), speculated to originate from strong magnetic interactions. ${ }^{(8)}$ Theoretical calculations have also shown that $\mathrm{CuFeS}_{2}$ has an antiferromagnetic configuration, resulting in the largest Seebeck coefficient and power factor. ${ }^{(9)}$ At low temperatures, the contribution of carrier-magnon interactions to the Seebeck coefficient was also indicated. ${ }^{(10)}$ Sulfides with a spinel structure, i.e., thiospinels, were generally observed to have poor thermoelectric properties. ${ }^{(14)}$ Good thermoelectric properties of $Z T=0.43$ were revealed in $\mathrm{CuCr}_{2} \mathrm{~S}_{4}$ by tuning the carrier concentration by $\mathrm{Sb}$ doping, whereby the intrinsic properties of a magnetic system with a relatively large effective mass were manifested at relatively large power factors. ${ }^{(11)} \mathrm{Cr}_{2} \mathrm{Se}$ is another magnetic system with a relatively good thermoelectric performance near RT, and importantly, $\mathrm{p}, \mathrm{n}$ tuning is possible without external element doping. ${ }^{(12)}$ In the Heusler alloy $\mathrm{Fe}_{2} \mathrm{VAl}$ system, where itinerant weak ferromagnetic behavior was engendered by doping, spin fluctuation was found to increase the Seebeck coefficient, for example by $50 \%$ at $400 \mathrm{~K} .^{(13)}$ Ultrahigh performance at $Z T>4$ has also been reported in related Heusler films. ${ }^{(15)}$ Inorganic thermoelectric thin films have been fabricated and investigated for various material systems, ${ }^{(16)}$ for example, thermoelectric thin films of oxides, ${ }^{(17,18)}$ borides, ${ }^{(19,20)}$ and stannides. ${ }^{(21)}$

Here, we report on the fabrication and thermoelectric properties of chromium silicide thin films. Chromium silicide is of interest for us, because for its future outlook, as a magnetic system $^{(22)}$ with high potentials as described above, and the thermoelectric properties of bulk $\mathrm{CrSi}_{2}$ were investigated previously. ${ }^{(23,24)}$ A relatively large power factor of $\sim 1 \mathrm{~mW} / \mathrm{m} \mathrm{K}^{2}$ has been reported for a pure bulk material at RT. ${ }^{(24)}$ Nakasawa et al. succeeded in increasing this to $\sim 1.4 \mathrm{~mW} / \mathrm{m} \mathrm{K}^{2}$ at RT via Mo doping. ${ }^{(25)}$ The reported high thermal conductivity of $12 \mathrm{~W} / \mathrm{m} \mathrm{K}$ at RT for the bulk material ${ }^{(25)}$ also makes it an attractive system that could benefit from being formatted into the thin film form. These are the reasons why we have focused on the chromium silicide system in our investigations of the fabrication of thin films and their thermoelectric properties.

\section{Materials and Methods}

Chromium silicide thin films were deposited on sapphire (0001) substrates (Shinkosha Co., Ltd.) using a molecular beam epitaxy (MBE; EV-500, Eiko Co., Ltd.) apparatus. Each sapphire substrate was degas-heated at $1000{ }^{\circ} \mathrm{C}$ for $1 \mathrm{~h}$ in vacuum before film deposition. Si and $\mathrm{Cr}$ were evaporated using special high-temperature K-cells, namely, MB-3000Si (Eiko Co., Ltd.) with a 
Ta crucible for Si and TUBO-e (CreaTec Fischer \& Co., GmbH) with a vitreous carbon crucible for $\mathrm{Cr}$, respectively. The deposition conditions are listed in Table 1. As common conditions, the growth time was $90 \mathrm{~min}$, and the heating temperature of the $\mathrm{Cr}$ cell was $1150{ }^{\circ} \mathrm{C}$. The film thickness was measured using a stylus profilometer (Dektak 6M, Bruker). The crystal structure was evaluated by X-ray diffraction (XRD), using a powder diffractometer (SmartLab 3, Rigaku Corp.).

The thermoelectric properties of the deposited thin films were measured using ZEM-3 (ULVAC). The cross-plane thermal conductivity was evaluated using a customized focused picosecond time-domain thermoreflectance (TD-TR) instrument (PicoTR, Picotherm Corp.) in a front-heating/front-detection configuration. ${ }^{(26-28)}$ A 100-nm-thick Pt thin film was deposited on chromium silicide thin film surfaces using a DC sputtering system to detect transient temperature changes. A $1550 \mathrm{~nm}$ infrared pulsed laser with a repetition frequency of $20 \mathrm{MHz}$ and a pulse duration of $0.5 \mathrm{ps}$ was used as a heat source. A $780 \mathrm{~nm}$ probe laser was used to detect thermoreflectance signals. Here, we assumed the specific heat of all films as $3 \mathrm{R}$ from the Dulong-Petit law $\left(0.575 \mathrm{~J} \mathrm{~g}^{-1} \mathrm{~K}^{-1}\right)$ for the calculation of the thermal conductivity.

\section{Results and Discussion}

Figures 1 and 2 show the XRD patterns of the MBE-grown chromium silicide thin films. As summarized in Table 1, various thin films were obtained under different thin film growth conditions.

The substrate temperatures of RT and $400{ }^{\circ} \mathrm{C}$ were apparently too low to achieve chromium silicide film growth, and phases were obtained from $600{ }^{\circ} \mathrm{C}$ and above. For substrate heating temperatures of 600 and $800{ }^{\circ} \mathrm{C}$, the majority phase was the $\mathrm{CrSi}$ metallic phase with significant $\mathrm{CrSi}_{2}$ growth. For 900 and $1000{ }^{\circ} \mathrm{C}$ substrate heating, $\mathrm{CrSi}_{2}$ was obtained as the majority phase, with $\mathrm{CrSi}$ and $\mathrm{Cr}_{5} \mathrm{Si}_{3}$ as minority phases.

In an attempt to reduce the amount of the metallic CrSi phase and relatively increase the amount of the main $\mathrm{CrSi}_{2}$ phase, the $\mathrm{Si}$ cell was heated up to $1525{ }^{\circ} \mathrm{C}$. As can be observed in

Table 1

Chromium silicide film growth parameters and phases.

\begin{tabular}{lccccc}
\hline Sample ID & $\begin{array}{c}\text { Substrate } \\
\text { temp. }\left({ }^{\circ} \mathrm{C}\right)\end{array}$ & $\begin{array}{c}\text { Si cell } \\
\text { temp. }\left({ }^{\circ} \mathrm{C}\right)\end{array}$ & Thickness $(\mathrm{nm})$ & $\begin{array}{c}\text { Majority } \\
\text { phase }\end{array}$ & $\begin{array}{c}\text { Minority } \\
\text { phases }\end{array}$ \\
\hline RT & $\mathrm{RT}$ & 1500 & - & - & - \\
400 & 400 & 1500 & - & - & - \\
$600 \mathrm{deg}$ & 600 & 1500 & 98.3 & $\mathrm{CrSi}$ & $\mathrm{CrSi}_{2}$ \\
$800 \mathrm{deg}$ & 800 & 1500 & 134.9 & $\mathrm{CrSi}$ & $\mathrm{CrSi}_{2}, \mathrm{Cr}_{5} \mathrm{Si}_{3}$ \\
$900 \mathrm{deg}$ & 900 & 1500 & 134.0 & $\mathrm{CrSi}_{2}$ & $\mathrm{CrSi}_{2} \mathrm{Cr}_{5} \mathrm{Si}_{3}$ \\
$1000 \mathrm{deg}$ & 1000 & 1500 & 106.6 & $\mathrm{CrSi}_{2}$ & $\mathrm{CrSi}_{5} \mathrm{Cr}_{5} \mathrm{Si}_{3}$ \\
$600 / 1525 \mathrm{deg}$ & 600 & 1525 & 107.1 & $\mathrm{CrSi}_{2}$ & $\mathrm{CrSi}_{3}$ \\
$800 / 1525 \mathrm{deg}$ & 800 & 1525 & - & $\mathrm{CrSi}_{2}$ & $\mathrm{CrSi}_{5} \mathrm{Cr}_{5} \mathrm{Si}_{3}$ \\
$900 / 1525 \mathrm{deg}$ & 900 & 1525 & 132.0 & $\mathrm{CrSi}_{2}$ & $\mathrm{CrSi}_{2} \mathrm{Cr}_{5} \mathrm{Si}_{3}$ \\
$1000 / 1525 \mathrm{deg}$ & 1000 & 1525 & 115.0 & $\mathrm{CrSi}_{2}$ & $\mathrm{CrSi}_{2} \mathrm{Cr}_{5} \mathrm{Si}_{3}$ \\
\hline
\end{tabular}



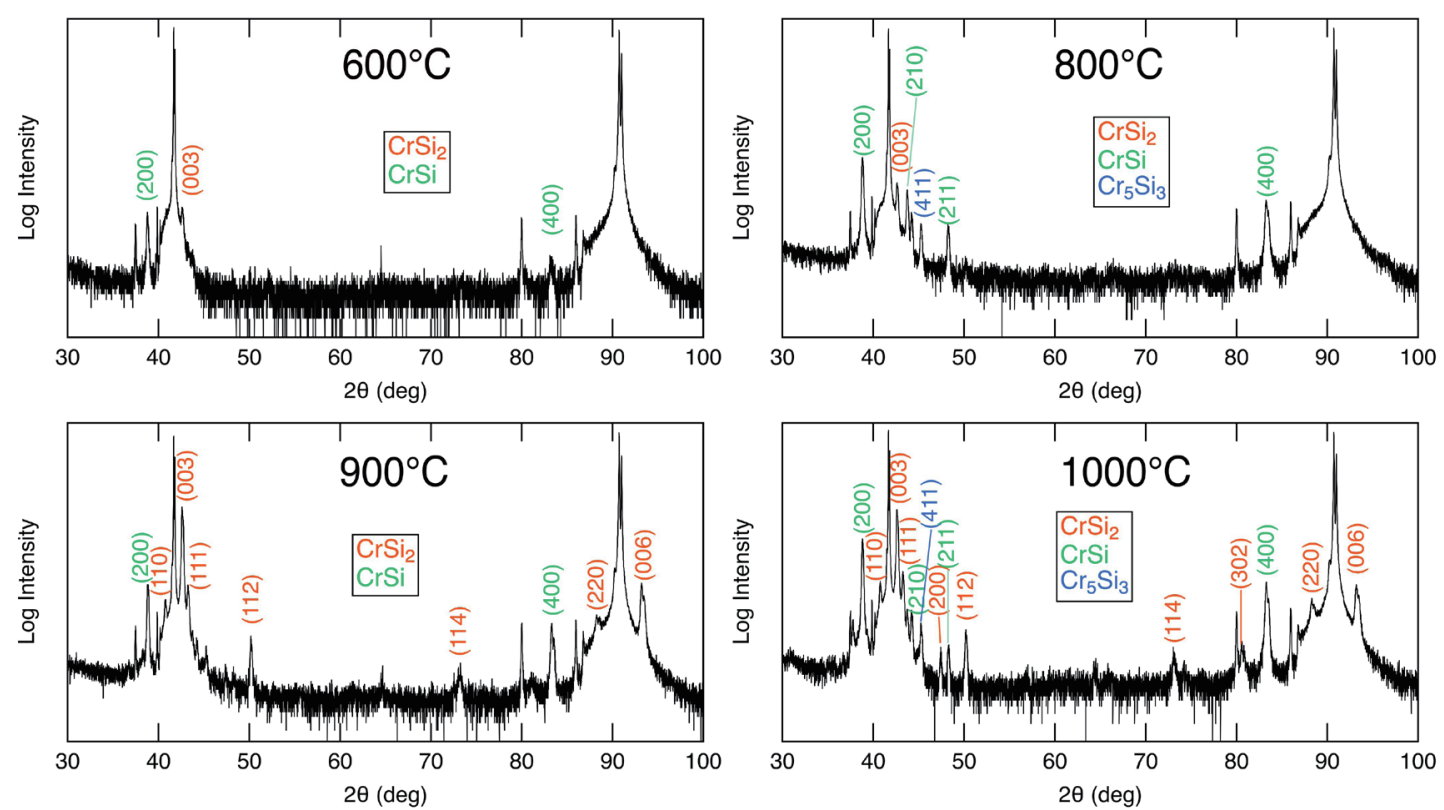

Fig. 1. (Color online) XRD patterns of chromium silicide thin films with $1500{ }^{\circ} \mathrm{C}$ Si cell heating. The indicated temperatures are the substrate heating temperatures.
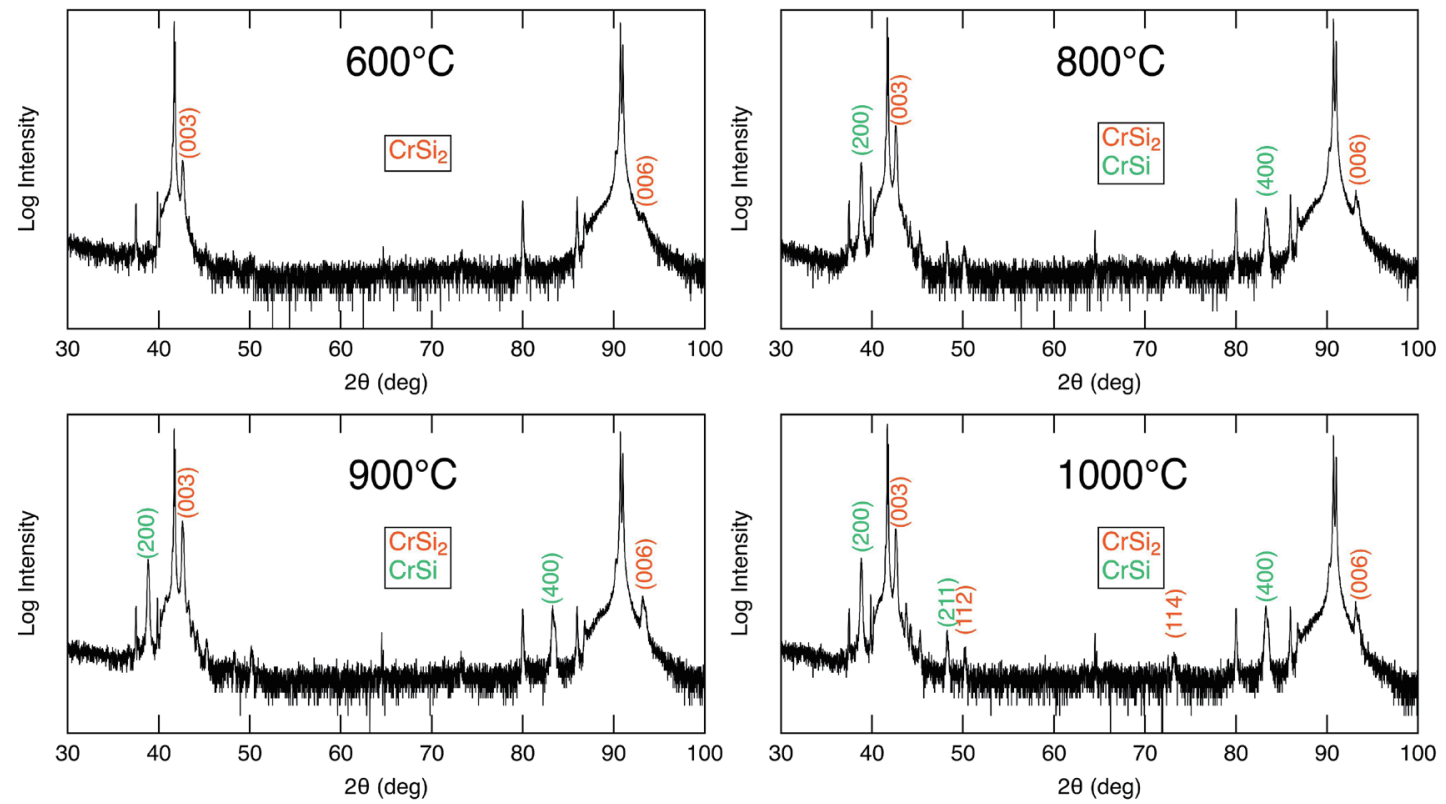

Fig. 2. (Color online) XRD patterns of chromium silicide thin films with $1525^{\circ} \mathrm{C}$ Si cell heating. The indicated temperatures are the substrate heating temperatures.

Fig. 2, this did not result in a relative reduction in the amount of the CrSi phase. Apparently, the opposite behavior was observed and the thermoelectric properties subsequently degraded. Namely, the power factor of the best sample in this series was around half that of Si heated 
at $1500{ }^{\circ} \mathrm{C}$. The tantalum material of our $\mathrm{Si}$ cell might have reacted with $\mathrm{Si}$ at higher temperatures, and it was not easy to tune the conditions further to optimize the $\mathrm{CrSi}_{2} \mathrm{MBE}$ thin film growth on our apparatus. This should be examined in future attempts together with doping to tune the properties.

The thermoelectric properties of the chromium silicide thin films, namely, the Seebeck coefficient, resistivity, and power factor, are shown in Fig. 3. The Seebeck coefficient of the $900 \mathrm{deg}$ film with substrate heating is larger than $140 \mu \mathrm{V} / \mathrm{K}$ near RT, slightly smaller but similar in magnitude to what was previously reported for bulk $\mathrm{CrSi}_{2} .{ }^{(24)}$ This can be considered to be the effect of the metallic CrSi minority phase. Reductions in the electrical conductivities and power factors of thin films of various thermoelectric materials compared

(a)

(b)

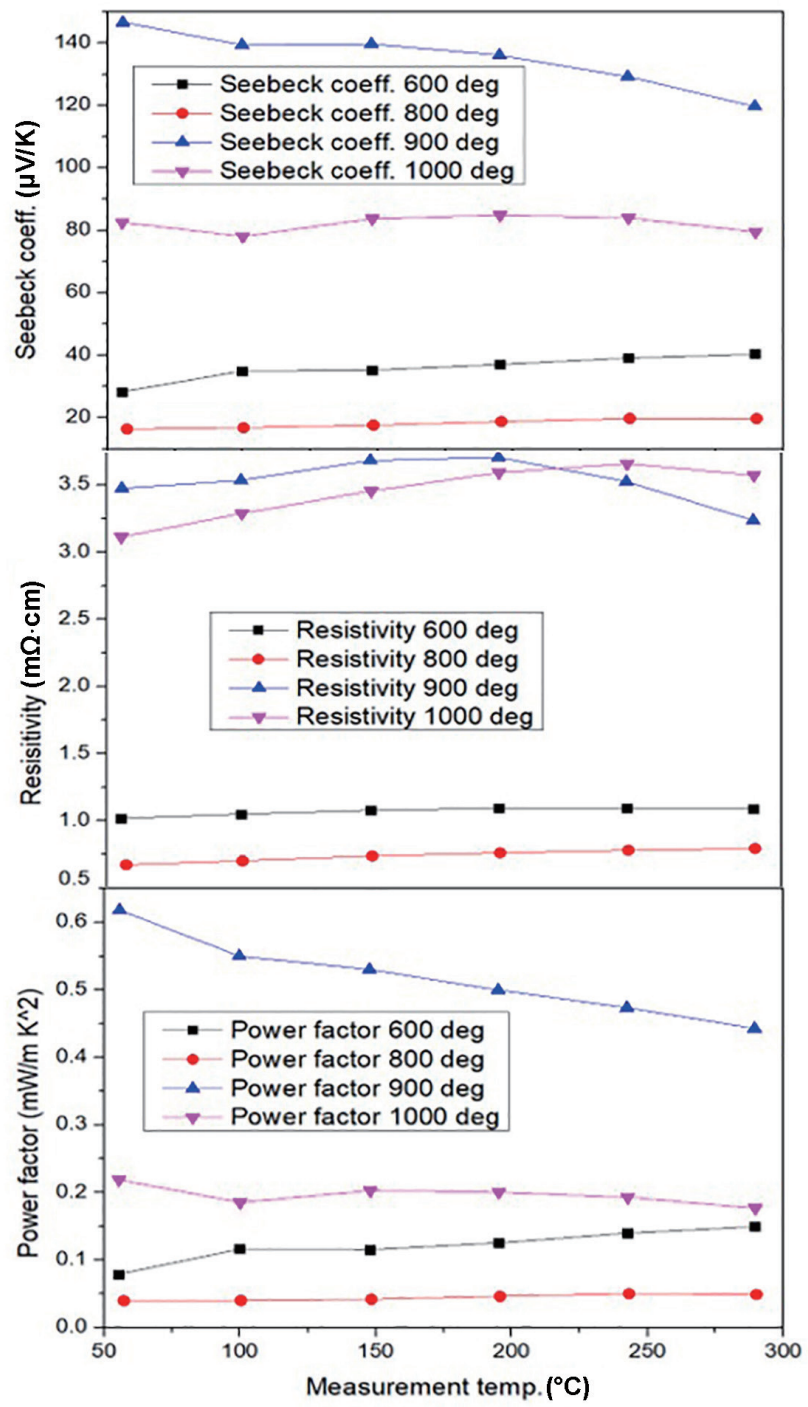

Fig. 3. (Color online) Thermoelectric properties: (a) Seebeck coefficient, (b) resistivity, and (c) power factor. 
with the bulk material, have typically been observed. ${ }^{(16)}$ The difference in polycrystalline quality between bulk samples and thin films can be a typical origin of this behavior, but the Seebeck coefficient is not affected. The 600 and 800 deg films with relatively high contents of metallic CrSi exhibit lower resistivities and smaller Seebeck coefficients. Metallic minority phases were previously observed in some cases to markedly increase the electrical conductivity and power factor; ${ }^{(29)}$ however, in this case, even with this possible benefit, the $900 \mathrm{deg}$ thin film exhibits a higher resistivity than the bulk, which is likely due to the detrimental thin-film effect mentioned previously. Although there is an apparatus limitation at present as discussed above, if we can finely tune the amount of the metallic $\mathrm{CrSi}$ phase in $\mathrm{CrSi}_{2}$ films, this can lead to the enhancement of the overall power factor. Such a metallic minority phase can generate a nonpercolating metallic partial network in the material, which will not markedly degrade the Seebeck coefficient, while enhancing the electrical conductivity significantly. ${ }^{(29)}$

The best power factor of the presently obtained chromium silicide films is $\sim 0.6 \mathrm{~mW} / \mathrm{m} \mathrm{K}^{2}$ near RT obtained for the $900 \mathrm{deg}$ thin film. This is smaller than $\sim 1 \mathrm{~mW} / \mathrm{m} \mathrm{K}^{2}$ reported for bulk $\mathrm{CrSi}_{2}$, but for thermoelectric thin films with abundant elements, it is a relatively large value at $\mathrm{RT}^{(17-21)}$

A significant increase in power factor to $\sim 1.4 \mathrm{~mW} / \mathrm{m} \mathrm{K}^{2}$ at RT was previously reported for Mo-doped bulk $\mathrm{CrSi}_{2}$, and doping experiments should be carried out in future studies. Furthermore, as mentioned in the introduction, the increase in the power factor has been achieved by considering magnetism, ${ }^{(5-9)}$ and as a future outlook, this possibility should also be investigated for chromium silicide thin films.

The behavior of the series of films with $1525{ }^{\circ} \mathrm{C}$ Si cell heating is as expected, with lower Seebeck coefficients due to the relatively higher content of metallic $\mathrm{CrSi}$ (Fig. 4). The maximum power factor obtained for the $1000 / 1525 \mathrm{deg}$ film is only around half that of the $1500{ }^{\circ} \mathrm{C}$ Si cell heating series.

The determined thermal conductivities of the selected thin film samples are listed in Table 2. The electronic thermal conductivity was determined using the Wiedemann-Franz law, where $\kappa_{E}=L \sigma T .2 .44 \times 10^{-8} \mathrm{~V}^{2} / \mathrm{K}^{2}$ was used as the Lorenz number $L$ here. $\kappa_{E}$ is relatively small, and it can be observed that the major part of thermal conductivity is the lattice thermal conductivity.

The thermal conductivity of bulk $\mathrm{CrSi}_{2}$ has been reported as $12 \mathrm{~W} / \mathrm{m} \mathrm{K}$ at $300 \mathrm{~K}^{(25)}$ Compared with the highest power factor film 900 deg sample, there is an approximately one-third reduction in thermal conductivity. The metallic CrSi minority phase is difficult to qualitatively gauge, since it can have opposite effects, namely, the thermal conductivity decreases via interfaces, but it also increases via highly conductive channels. In any case, all the chromium silicide films synthesized under standard conditions exhibited a lower thermal conductivity than bulk $\mathrm{CrSi}_{2}$, so the thin-film format is effective in reducing the thermal conductivity.

We consider other possible effects of the differences in the thickness between the thin films, from $98.3 \mathrm{~nm}$ to $134.9 \mathrm{~nm}$, on the thermoelectric properties measured. The measurements themselves should not have any effect. Regarding the intrinsic properties, even for the thinnest film, in this range we do not expect any specific electronic effects that are not observed in 
(a)

(b)

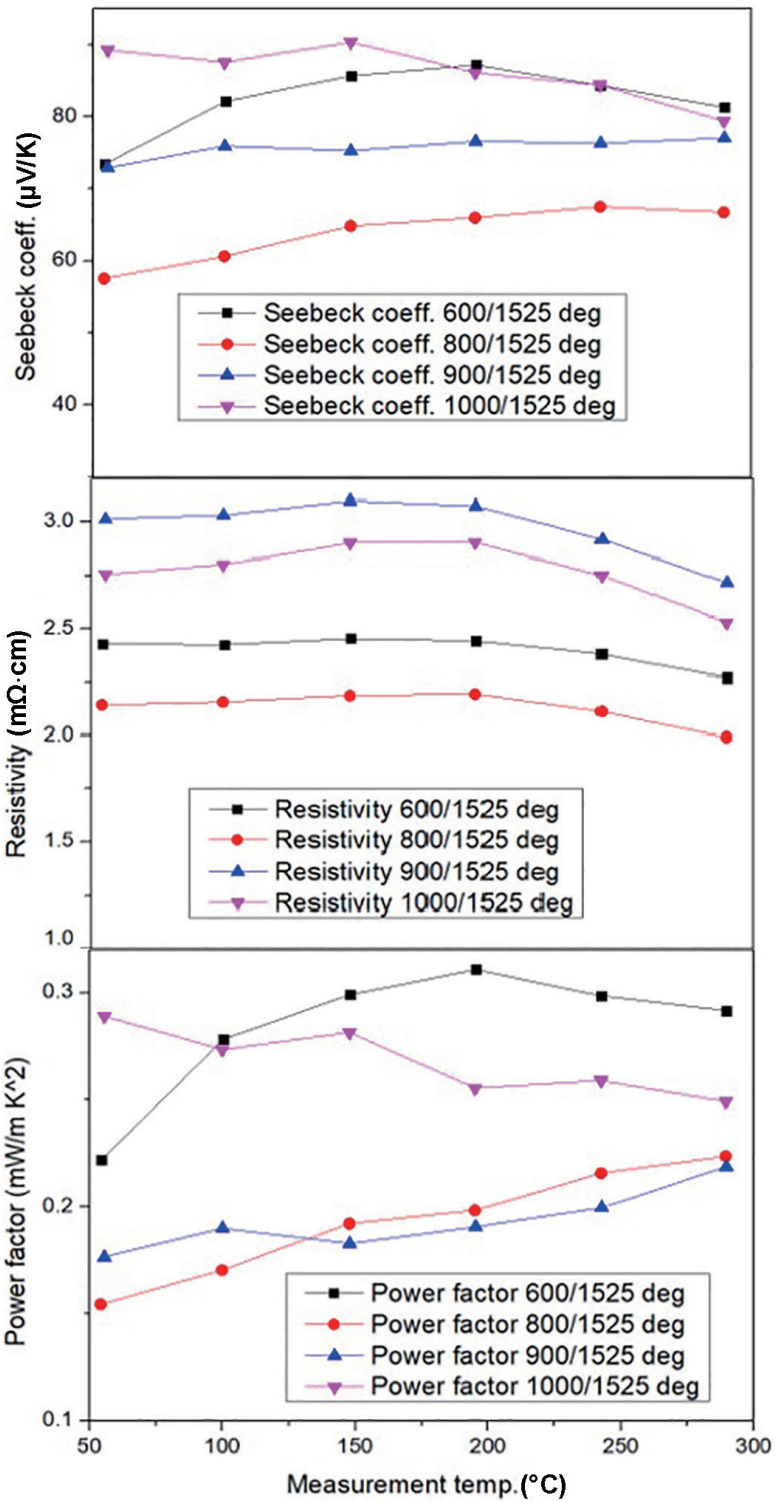

Fig. 4. (Color online) Thermoelectric properties: (a) Seebeck coefficient, (b) resistivity, and (c) power factor.

Table 2

Thermal conductivities of chromium silicide films.

\begin{tabular}{lccc}
\hline Sample ID & $\begin{array}{c}\text { Thermal diffusivity } \\
\text { at } 300 \mathrm{~K}\left(10^{-6} \mathrm{~m}^{2} / \mathrm{s}\right)\end{array}$ & $\begin{array}{c}\text { Thermal conductivity } \kappa \\
\text { at } 300 \mathrm{~K}(\mathrm{~W} / \mathrm{mK})\end{array}$ & $\begin{array}{c}\text { Electronic thermal conductivity } \kappa_{E} \\
\text { at } 323 \mathrm{~K}(\mathrm{~W} / \mathrm{mK})\end{array}$ \\
\hline $600 \mathrm{deg}$ & 2.85 & 7.20 & 0.79 \\
$800 \mathrm{deg}$ & 4.05 & 10.23 & 1.19 \\
$900 \mathrm{deg}$ & 3.33 & 8.40 & 0.23 \\
$1000 \mathrm{deg}$ & 3.01 & 7.61 & 0.26 \\
$600 / 1525 \mathrm{deg}$ & 2.73 & 6.90 & - \\
$900 / 1525 \mathrm{deg}$ & 3.65 & 9.22 & - \\
$1000 / 1525 \mathrm{deg}$ & 3.54 & 8.95 & - \\
\hline
\end{tabular}


the bulk form, such as quantum confinement or electronic structure modulation. However, according to a previous report on the theoretical evaluation of the thermal conductivity of $\mathrm{CrSi}_{2}$, ${ }^{(30)}$ phonons with a mean free path of about $100 \mathrm{~nm}$ do not have significant contributions to thermal transport. Therefore, the differences in the thickness between our samples are not expected to have any effect on the thermoelectric properties.

\section{Conclusions}

We fabricated chromium silicide thin films by MBE. The film with the highest thermoelectrical performance had $\mathrm{CrSi}_{2}$ as the main phase. The highest power factor of more than $0.6 \mathrm{~mW} / \mathrm{m} \mathrm{K}^{2}$ at RT was obtained for the chromium silicide film with a deposition temperature of $900{ }^{\circ} \mathrm{C}$ and a $\mathrm{Si}$ cell heating temperature of $1500{ }^{\circ} \mathrm{C}$. For thermoelectric thin films with abundant elements, the obtained power factor was relatively large, which made the thin films promising systems to be investigated further. These thin films exhibited a thermal conductivity that was approximately one-third that of bulk $\mathrm{CrSi}_{2}$. Bulk $\mathrm{CrSi}_{2}$ exhibited significant increases in power factor via doping; this should also be further examined in the fabricated thin films, together with an investigation on any correlation with magnetic properties, and their tuning.

\section{Acknowledgments}

This work was supported by Japan Science and Technology Agency (JST), Mirai Program Grant Number JPMJMI19A1, CREST JPMJCR19Q4, and JSPS KAKENHI Grant Number JP17H02749 and JP16H06441.

\section{References}

1 T. Mori and S. Priya: MRS Bull. 43 (2018) 176. https://doi.org/10.1557/mrs.2018.32

2 I. Petsagkourakis, K. Tybrandt, X. Crispin, I. Ohkubo, N. Satoh, and T. Mori: Sci. Tech. Adv. Mater. 19 (2018) 836. https://doi.org/10.1080/14686996.2018.1530938

3 J. Mao, Z. Liu, J. Zhou, H. Zhu, Q. Zhang, G. Chen, and Z. Ren: Adv. Phy. 67 (2018) 69. https://doi.org/10.1080 /00018732.2018.1551715

4 T. Mori: Small 13 (2017) 1702013. https://doi.org/10.1002/smll.201702013

5 F. Ahmed, N. Tsujii, and T. Mori: J. Mater. Chem., A. 5 (2017) 7545. https://doi.org/10.1039/C6TA11120C

6 S. Acharya, S. Anwar, T. Mori, and A. Soni: J. Mater. Chem. C. 6 (2018) 6489. https://doi.org/10.1039/ c8tc00788h

7 J. B. Vaney, S. A. Yamini, H. Takaki, K. Kobayashi, N. Kobayashi, and T. Mori: Mater. Today Phys. 9 (2019) 100090. https://doi.org/10.1016/j.mtphys.2019.03.004

8 N. Tsujii and T. Mori: Appl. Phys. Exp. 6 (2013) 043001. https://doi.org/10.7567/APEX.6.043001

9 H. Takaki, K. Kobayashi, M. Shimono, N. Kobayashi, K. Hirose, N. Tsujii, and T. Mori: Mater. Today Phys. 3 (2017) 85. https://doi.org/10.1016/j.mtphys.2017.12.006

10 R. Ang, A. U. Khan, N. Tsujii, K. Takai, R. Nakamura, and T. Mori: Angew. Chem. Int. Ed. 54 (2015) 12909. https://doi.org/10.1002/anie.201505517

11 A. U. Khan, R. A. R. A. Orabi, A. Pakdel, J. B. Vaney, B. Fontaine, R. Gautier, J. F. Halet, S. Mitani, and T. Mori: Chem. Mater. 29 (2017) 2988. https://doi.org/10.1021/acs.chemmater.6b05344

12 Q. Guo, D. Berthebaud, J. Ueda, S. Tanabe, A. Miyoshi, K. Maeda, and T. Mori: J. Mater. Chem. C. 7 (2019) 8269. https://doi.org/10.1039/c9tc01634a

13 N. Tsujii, A. Nishide, J. Hayakawa, and T. Mori: Sci. Adv. 5 (2019) eaat5935. https://doi.org/10.1126/sciadv. aat5935 
14 G. J. Snyder, T. Caillat, and J. P. Fleurial: MRS Proc. (MRS, 2000) Z3.3. https://doi.org/10.1557/PROC626-Z3.3

15 B. Hinterleitner, I. Knapp, M. Poneder, Yongpeng Shi, H. Müller, G. Eguchi, C. Eisenmenger-Sittner, M. Stöger-Pollach, Y. Kakefuda, N. Kawamoto, Q. Guo, T. Baba, T. Mori, Sami Ullah, Xing-Qiu Chen, and E. Bauer: Nature 576 (2019) 85. https://doi.org/10.1038/s41586-019-1751-9

16 P. Mele, D. Narducci, M. Ohta, K. Biswas, J. Morante, S. Saini, and T. Endo: Thermoelectric Thin Films Materials and Devices (Springer, 2019). https://doi.org/10.1007/978-3-030-20043-5

17 P. Mele, S. Saini, H. Honda, K. Matsumoto, K. Miyazaki, H. Hagino, and A. Ichinose: Appl. Phys. Lett. 102 (2013) 253903. https://doi.org/10.1063/1.4812401

18 Y. Hirose, M. Tsuchii, K. Shigematsu, Y. Kakefuda, T. Mori, and T. Hasegawa: Appl. Phys. Lett. 114 (2019) 193903. https://doi.org/10.1063/1.5089679

19 S. Ghamaty, J. C. Bass, and N. B. Elsner, and edited by D. M. Rowe: Thermoelectrics Handbook, Micro to Nano (Taylor \& Francis, London, 2006) p. 57.

20 G. P. L. Guélou, M. Martirossyan, K. Ogata, I. Ohkubo, Y. Kakefuda, N. Kawamoto, Y. Kitagawa, J. Ueda, S. Tanabe, K. Maeda, K. Nakamura, T. Aizawa, and T. Mori: Materialia 1 (2018) 244. https://doi.org/10.1016/ j.mtla.2018.06.003

21 T. Aizawa, I. Ohkubo, M. Lima, T. Sakurai, and T. Mori: J. Vac. Sci. Technol. A. 37 (2019) 061513. https://doi. org/10.1116/1.5122844

22 D. J. Singh and D. Parker: Sci. Rep. 3 (2013) 3517. https://doi.org/10.1038/srep03517

23 I. Nishida: J. Mater. Sci. 7 (1972) 1119. https://doi.org/10.1007/BF00550193

24 T. Dasgupta, J. Etourneau, B. Chevalier, S. F. Matar, and A. M. Umarji: J. Appl. Phys. 103 (2008) 113516. https://doi.org/10.1063/1.2917347

25 H. Nakasawa, T. Takamatsu, Y. Iijima, K. Hayashi, and Y. Miyazaki, Trans. Mater. Res. Soc. Jpn. 43 (2018) 85. https://doi.org/10.14723/tmrsj.43.85

26 Y. Kakefuda, K. Yubuta, T. Shishido, A. Yoshikawa, S. Okada, H. Ogino, N. Kawamoto, T. Baba, and T. Mori: APL Mater. 5 (2017) 126103. https://doi.org/10.1063/1.5005869

27 M. Piotrowski, M. Franco, V. Sousa, J. Rodrigues, F. L. Deepak, Y. Kakefuda, T. Baba, N. Kawamoto, B. Owens-Baird, P. Alpuim, K. Kovnir, T. Mori, and Y. V. Kolenko: J. Phys. Chem. C 122 (2018) 27127. https:// doi.org/10.1021/acs.jpcc.8b04104

28 R. Daou, F. Pawula, O. Lebedev, D. Berthebaud, S. Hebert, A. Maignan, Y. Kakefuda, and T. Mori: Phys. Rev. B: Condens. Matter 99 (2019) 085422. https://doi.org/10.1103/PhysRevB.99.085422

29 T. Mori and T. Hara: Scripta Mater. 111 (2016) 44. https://doi.org/10.1016/j.scriptamat.2015.09.010

30 H. Nakasawa, K. Hayashi, T. Takamatsu, and Y. Miyazaki, J. Appl. Phys. 126 (2019) 025105. https://doi. org/10.1063/1.5096458 